\title{
ANALISIS PENERAPAN IMBALAN PASCAKERJA PADA KARYAWAN PT. MOY VERONIKA
}

\author{
Monalisa $^{1}$, Treesje Runtu ${ }^{2}$, Robert Lambey $^{3}$ \\ ${ }^{1,2,3}$ Jurusan Akuntansi, Fakultas Ekonomi dan Bisnis, Universitas Sam Ratulangi, Jl. Kampus Bahu, Manado, \\ 95115, Indonesia \\ E-mail : monalisaree@yahoo.com
}

\begin{abstract}
Employee Benefits consist of short-term benefit, long-term benefit, post-employment benefit and severance pay. Regarding the ease and also the economic safety of the employee, company is obligated to prepare and allocate the post-employment benefit and also declare their will to pay at the end of the employee's work. This research aims to analyze the implementation of post-employment benefit on the employees of PT. Moy Veronika based on PSAK 24 and UUK No. 13 Tahun 2003. The method used in this research is qualitative descriptive research method. The result of this research shows that the implementation of the post-employment benefit by PT. Moy Veronika hasn't been in accordance with PSAK 24, in which the factor that caused the absence of recording of the post-employment benefit transaction is owner's ignorance in reserving the post-employment benefit due to the their kinship with the employees and the implementation of distributing the post-employment benefit in PT. Moy Veronika is already in accordance with UUK No. 13 Tahun 2003, in which the termination of work occurs due to 1) Resignation; 2) Death; 3) Pension; 4) Prolonged illness/disability, the company has fulfilled its obligation in distributing the postemployment benefit.
\end{abstract}

Keyword : post-employment benefit

\section{PENDAHULUAN}

Sebagian besar masyarakat Indonesia memiliki pekerjaan sebagai seorang pekerja atau buruh, dimana pekerja atau buruh sudah menjadi salah satu lapangan pekerjaan yang mempengaruhi perekonomian negara. Pada umumnya pekerja diberikan pekerjaan oleh pemberi kerja atau perusahaan yang adalah sebuah lembaga yang terdapat banyak orang ataupun karyawan, khususnya yang merupakaan individu yang berasal dari latar belakang yang berbeda lingkungan, agama, pendidikan, dan lain-lain (Darodjat, 2015 :1).

Semua perusahaan membutuhkan tenaga kerja untuk kegiatan operasionalnya. Perusahaan berlaku sebagai pemberi kerja, dan tenaga kerja berlaku sebagai penerima kerja. Sebagai pemberi kerja, perusahaan harus memberikan imbalan kerja atas jasa yang sudah diberikan tenaga kerja bagi operasional perusahaan (Arine, 2016). Imbalan kerja juga dapat berdampak kurang baik pada efektivitas perusahaan dan kinerja pekerja jika tidak diterapkan dengan baik. Lebih lanjut lagi menurut Watung (2016) perlakuan yang tidak tepat terhadap pekerja dapat berdampak negatif untuk perusahaan, dikarenakan dapat mendorong pekerja melakukan pemogokan atau kecurangan seperti korupsi dan penyeludupan yang dapat merugikan perusahaan.

Perusahaan seharusnya menerapkan akuntansi mengenai imbalan kerja yang didalamnya termasuk mengenai imbalan pascakerja, karena imbalan kerja merupakan bagian dari keuangan perusahaan dalam pembiayaan operasional dan harus diungkapkan secara transparan dalam laporan keuangan. Akuntansi perusahaan diatur dalam Standar Akuntansi Keuangan (SAK), standar Akutansi merupakan pedoman umum penyusunan laporan keuangan yang merupakan pernyataan resmi tentang masalah akuntansi tertentu yang dikeluarkan oleh badan yang berwenang dan berlaku dalam lingkungan tertentu. Standar 
Akuntansi menjadi dasar dalam penyajian informasi laporan keuangan suatu kegiatan usaha. Menurut Anantharaman \& Chuk (2015) Accounting standards govern the measurement, recognition, and presentation of accrual accounting assets, liabilities, and income, and do not have direct effects on cash flows.

\section{TINJAUAN PUSTAKA}

\subsection{Pengertian akuntansi dan akuntansi keuangan}

Menurut Lam dan Lau (2012) akuntansi adalah sistem pencatatan dan ringkasan bisnis dan transaksi keuangan serta menganalisis, memverifikasi, dan melaporkan hasilnya. Akuntansi juga bisa didefinisikan sebagai konsep informasi maupun sistem informasi. Sebagai konsep informasi, akuntansi merupakan kegiatan jasa yang menyediakan informasi kuantitatif terutama yang bersifat keuangan, tentang kesatuan-kesatuan ekonomi yang dimaksudkan agar bermanfaat dalam pengambilan keputusan ekonomi, dalam menetapkan pilihan yang pantas diantara berbagai alternatif tindakan. Sedangkang sebagai sistem informasi, akuntansi merupakan proses yang menjalin sumber informasi laporan kepada para pengguna informasi akuntansi atau kepada pihak-pihak yang memiliki kepentingan (stakeholders) terhadap hasil kinerja dan kondisi keuangan perusahaan. Dari beberapa pengertian diatas dapat disimpulkan bahwa akuntansi merupakan kegiatan jasa dengan proses yang sudah ada sedemikian rupa dalam mencatat, mengikhtisarkan, melaporkan data keuangan dan menghasilkan informasi kepada pihak-pihak yang memerlukan, dan hasil dari mengelola data keuangan tersebut dapat menjadi informasi yang berguna, serta dapat di pertanggungjawabkan. Lebih umumnya akuntansi merupakan bahasa bisnis yang digunakan oleh pihak-pihak yang berkepentingan untuk mengkomunikasikan keuangan yang digunakan dalam usaha mereka.

Akuntansi keuangan merupakan salah satu bagian dari akuntansi yang berhubungan dengan penyajian laporan keuangan perusahaan kepada pihak eksternal berupa laporan neraca, laba rugi, perubahan modal, dan arus kas kepada pemegang saham, kreditor, atau investor, khususnya tentang profitabilitas dan kredibilitas perusahaan, kepada supplier, dan pemerintah. Definisi-definisi ini didukung oleh pendapat Hery (2013) financial accounting memberikan informasi akuntansi keuangan bagi kepentingan eksternal. Menurut Reeve, et al (2012 :10) Akuntansi keuangan (financial accounting) sangat terkait dengan pencatatan dan pelaporan data dan aktivitas ekonomi suatu perusahaan. Selain laporan ini berguna bagi manager, laporan tersebut juga menjadi laporan utama bagi pemilik usaha, kreditur, badan pemerintah dan masyarakat. Tujuan akuntansi keuangan adalah menyediakan laporan yang berguna untuk kebutuhan tersebut.

\subsection{Imbalan Kerja}

Imbalan kerja juga merupakan segala sesuatu yang diberikan kepada karyawan dalam bentuk fisik dan non fisik serta harus diakui didalam laporan keuangan, dan sebagai liabilitas, imbalan kerja juga menurut standar akuntansi harus di cadangkan agar tidak mengganggu arus kas entitas dalam laporan keuangan perusahaan. Didalam PSAK 24 (2014, par.08) Definisi imbalan kerja: Imbalan kerja adalah seluruh bentuk imbalan yang diberikan entitas dalam pertukaran atas jasa yang diberikan oleh pekerja atau untuk terminasi kontrak kerja.

\subsubsection{Beban Imbalan Kerja}

Beban imbalan kerja adalah suatu bentuk pengakuan perusahaan atas pertukaran jasa yang diberikan oleh pekerja/buruh yang sudah memberikan jasanya kepada entitas dengan jangka waktu yang sudah di tentukan. Menurut Paath (2015) beban imbalan kerja adalah suatu bagian dari beban perusahaan yang harus diakui pada laporan laba/rugi komprehensif. Beban imbalan kerja baik jangka pendek maupun jangka panjang harus dicadangkan sebagai suatu kewajiban setiap bulannya sebagai konsekuensi adanya jasa yang diberikan pekerja 
kepada perusahaan. Pencadangan dilakukan agar laporan keuangan menyajikan informasi yang relevan bagi pengambil keputusan (Paath, 2015).

\subsubsection{Jenis Imbalan Kerja}

Ada 4 (empat) jenis imbalan kerja, yaitu:

1. Imbalan kerja jangka pendek

Imbalan kerja yang di berikan kepada karyawan dengan jatuh temponya sekurangkurangnya dari 12 (dua belas) bulan. Contoh dari imbalan kerja jangka pendek ini adalah; gaji, iuran jaminan sosial, cuti tahunan, cuti sakit, bagi laba dan bonus (jika terutang dalam waktu 12 bulan pada periode akhir pelaporan), dan imbalan yang tidak berbentuk uang (imbalan kesehatan, rumah, mobil, barang, dan jasa yang diberikan secara cuma-cuma atau melalui subsidi).

2. Imbalan pascakerja

Imbalan pascakerja adalah imbalan kerja yang diterima pekerja atau keluarga maupun yang menjadi relasi pekerja setelah sudah tidak aktif lagi bekerja, berhentinya pekerja dengan alasan-alasan pasti dalam pemberhentian kerja yang pastinya tidak merugikan salah satu pihak, antara pekerja atau pemberi kerja, salah satu contohnya pekerja mengalami kecelakaan kerja dan mengakibatkan pekerja cacat (keterbatasan fisik) dan tidak dapat melanjutkan pekerjaanya. Contoh dari imbalan pascakerja ini adalah; imbalan pensiun.

3. Imbalan kerja jangka panjang

Imbalan kerja yang jatuh temponya lebih dari 12 (dua belas) bulan. Berikut contoh dari imbalan kerja yang dimaksud; cuti besar/cuti panjang, penghargaan masa kerja berupa sejumlah uang atau berupa cendramata seperti pin/cincin dan lain-lain.

4. Pesangon

Imbalan yang diberikan karena karyawan menerima tawaran mengundurkan diri secara sukarela, untuk perencanaan perusahaan yang sudah jelas.

\subsection{Imbalan Pascakerja}

Imbalan pascakerja, seperti berikut ini:

(i) imbalan purnakarya (contohnya pensiun dan pembayaran lump sun pada saat purnakarya); dan

(ii) imbalan pascakerja lain, seperti asuransi jiwa pascakerja, dan fasilitas pelayanan kesehatan pascakerja.

Di dalam Undang-Undang Ketenagakerjaan terdapat pembahasan mengenai imbalan pascakerja, yaitu imbalan yang harus diberikan perusahaan kepada karyawan ketika karyawan sudah berhenti bekerja (pasca kerja = setelah kerja). Imbalan pascakerja yang tercantum di perundang-undangan ketenagakerjaan adalah:

1. Imbalan pascakerja karena karyawan mengundurkan diri;

2. Imbalan pascakerja karena karyawan meninggal dunia;

3. Imbalan pascakerja karena karyawan pensiun; dan

4. Imbalan pascakerja karena karyawan mengalami kecelakaan kerja dan mengakibatkan sakit berkepanjangan/cacat.

\subsubsection{Program Iuran Pasti dan Program Imbalan Pasti}

Program iuran pasti adalah program imbalan pascakerja dengan jumlah imbalan yang diterima pekerja ditentukan oleh jumlah iuran yang dibayar oleh entitas (dan mungkin juga oleh pekerja) ke program imbalan pascakerja atau perusahaan asuransi, ditambah hasil investasi iuran tersebut. PSAK 24 menyatakan bahwa ketika pekerja telah memberikan jasa kepada perusahaan selama satu periode, perusahaan mengakui iuran terutang kepada program iuran pasti atas jasa pekerja:

1. Sebagai liabilitas (beban akrual) setelah dikurangi dengan iuran yang telah dibayar. Jika iuran yang telah dibayar tersebut melebihi iuran terutang untuk jasa sebelum 
akhir peiode pelaporan, maka entitas mengakui kelebihan tersebut sebagai aset (beban dibayar dimuka) sepanjang kelebihan tersebut akan mengurangi pembayaran iuran masa depan atau pembayaran kembali dalam bentuk kas.

2. Sebgai beban, kecuali jika PSAK lain mensyaratkan atau mengizinkan iuran tersebut untuk dimasukkan dalam biaya perolehan aset.

Program imbalan pasti adalah program imbalan pascakerja yang bukan merupakan program iuran pasti. Pada dasarnya, program imbalan pasti menyediakan imbalan yang dijanjikan kepada karyawan di akhir masa kerja dan perusahaan harus memastikan telah membayar cukup iuran untuk memenuhi beban imbalan yang ditentukan dalam program itu. Proses akuntansi oleh perusahaan untuk program imbalan pasti meliputi tahap-tahap berikut:

1. Menentukan defisit atau surplus dengan menggunakan teknik aktuarial, metode project unit credit.

2. Menentukan jumlah liabilitas (aset) imbalan pasti neto sebagai jumlah defisit atau surplus.

3. Menentukan jumlah yang harus diakui dalam laba rugi.

4. Menentukan pengukuran kembali atas liabilitas (aset) imbalan pasti neto, yang akan diakui sebagai penghasilan komprehensif lain

\subsection{UUK No.13 Tahun 2003}

1. Pasal 156

Didalam pasal ini, pemberi kerja dihimbau untuk memperhatikan jumlah uang yang akan diberikan berdasarkan masa kerja kepada pekerja, pasal ini juga menjadi landasan perhitungan untuk pemberian imbalan pascakerja menurut jenis pascakerja pekerja.

2. Pasal 162 (mengundurkan diri/resign).

Pasal ini mengatur tentang pemberian imbalan pascakerja yang diakibatkan pekerja tersebut mengundurkan diri dari pekerjaanya yang tugas dan fungsinya tidak mewakili kepentingan pemberi kerja.

3. Pasal 166 (meninggal dunia)

Pasal ini mengatur tentang pemberian imbalan kepada keluarga pekerja yang dimana pekerja ini tidak bisa melanjutkan pekerjaan yang diakibatkan karena pekerja meninggal dunia.

4. Pasal 167 (pensiun)

Pasal ini mengatur pemberian imbalan kepada pekerja yang sudah memasuki usia pensiun dan tidak mampu lagi untuk melanjutkan pekerjaan.

5. Pasal 172 (sakit berkepanjangan/cacat)

Dalam pasal ini, diatur pemberian imbalan kepada pekerja yang mengalami sakit berkepanjangan dan tidak dapat melanjutkan pekerjaan karena mengalami keterbatasan fisik.

\subsection{Penelitian terdahulu}

Beberapa penelitian terdahulu yang penulis jadikan sebagai bahan pertimbangan dalam melakukan penelitian di PT. Moy Veronika. Penelitian yang dilakukan oleh Chintya Lidya Amelia Paath tahun 2015, tentang evaluasi penerapan PSAK 24 revisi 2010 mengenai imbalan kerja khususnya imbalan setelah bekerja, yang dilaksanakan pada Bank Sulut menyatakan bahwa secara umum bank telah menerapkan pengakuan dan pengukuran imbalan paska kerja sesuai PSAK 24 Revisi 2010. Pada peneletian yang dilakukan oleh analisis pengakuan, pengukuran, dan pengungkapan imbalan kerja berdasarkan PSAK No.24 tentang imbalan kerja, yang dilaksanakan pada PT. Hasjrat Abadi cabang Manado, hasil penelitian menunjukan bahwa objek telah menerapkan dengan baik pengakuan, pengukuran dan pengungkapan imbalan kerja jangka pendek dan imbalan pasca kerja sesuai PSAK No. 24. 


\section{METODE PENELITIAN}

\subsection{Jenis Penelitian}

Penelitian ini merupakan jenis penelitian deskriptif kualitiatif. Menurut Sadarmayanti \& Hidayat (2011: 33) penelitian deskriptif adalah suatu metode dalam pencarian fakta status sekelompok manusia, suatu objek, suatu kondisi, suatu sistem pemikiran ataupun suatu peristiwa pada masa sekarang dengan interpretasi yang tepat. Sedangkan menurut Suryabrata (2013: 75) penelitian deskriptif merupakan jenis penelitian yang tujuannya untuk membuat pecandraan secara sistematis, faktual, dan akurat mengenai fakta-fakta dan sifat-sifat populasi atau daerah tertentu.

\subsection{Waktu dan Tempat Penelitian}

Penelitian ini mengambil data di PT. Moy Veronika yang beralamat di Jl.Sea Lingkungan II Nomor 36 Malalayang Manado, Sulawesi Utara. Waktu penelitiam dilaksanakan selama 5 bulan yaitu Februari 2017 sampai dengan Juni 2017.

\subsection{Metode Analisis}

Metode analisis yang dipakai dalam penelitian ini adalah analisis deskriptif. Penelitian deskriptif adalah suatu metode yang bertujuan untuk menggambarkan suatu keadaan perusahaan secara sistematis, aktual dan akurat dengan cara mengumpulkan data berdasarkan data yang nampak dalam perusahaan atau organisasi, dimana fakta tersebut dikumpulkan, diolah dan dianalisis sehingga dapat memberikan saran-saran untuk masa yang akan datang (Sugiyono 2014: 206).

\section{HASIL ANALISIS DAN PEMBAHASAN}

\subsection{Hasil analisis}

Hasil penelitian yang di dapatkan dengan melakukan serangkaian analisis atas tata cara pemberian imbalan pascakerja di PT. Moy Veronika terhadap karyawan yang sudah berhenti bekerja, sesuai dengan rumusan masalah dan tujuan penelitian yang telah dirumuskan, maka disajikanlah hasil sebagai berikut:

1. Dari hasil wawancara dengan manager dan bendahara, perusahaan tidak menggunakan dasar dalam pemberian imbalan pascakerja. Perusahaan tidak menegaskan suatu standar peraturan dalam pemberian imbalan pascakerja kepada pekerja yang sudah tidak lagi bekerja, karena dari awal perusahaan berdiri, pemberian imbalan pascakerja ditangani langsung oleh owner perusahaan sendiri.

2. Dari hasil wawancara dengan owner dan bagian keuangan perusahaan pada pencatatan keuangan perusahaan, imbalan pascakerja juga tidak diakui sebagai kewajiban. Ketidaktahuan tentang PSAK 24 yang seharusnya perusahaan mengakui dan menjadikan imbalan pascakerja sebagai kewajiban perusahaan, hal ini dikarenakan owner dan bagian keuangan perusahaan tidak mempunyai dasar pendidikan dibagian ekonomi, serta kurangnya akses informasi yang masuk seperti sosialisasi kesejahteraan perusahaan serta karywannya, atau seminar tentang pengaruh kesesuaian laporan keuangan dengan standar akuntansi yang menguntungkan perusahaan.

3. Dari hasil observasi terhadap manajemen sumber daya manusia perusahaan tidak mendaftarkan karyawan sebagai peserta jaminan. Didapati entitas tidak mengikutsertakan pegawai dalam program jaminan sosial dikarenakan owner memiliki hubungan saudara dengan para karyawannya, yang membuat owner merasa tidak terlalu perlu untuk mensejahterakan para karyawan dengan mengikutsertakan pekerjanya sebagai peserta jaminan sosial yang merupakan keluarga, yang dimana menurut owner keutungan dari perusahaan secara tidak langsung menjadi keutungan dari para pekerja yang merupakan saudara dari owner sendiri. 


\subsection{Pembahasan}

\subsubsection{Penerapan Imbalan Pascakerja sesuai dengan PSAK 24}

Dari hasil wawancara pada PT. Moy Veronika, entitas tidak menerapkan dan tidak mengalokasikan dana dari kas perusahaan khusus untuk program iuran pasti imbalan pascakerja bagi karyawannya, sehingga tidak dilakukan pencatatan mengenai akuntansi imbalan pascakerja. Tidak adanya pengalokasian dana dari kas perusahaan khusus untuk program iuran pasti dikarenakan owner tidak memiliki pengetahuan tentang anjuran pengalokasian dana dari kas perusahaan untuk imbalan pascakerja terhadap karyawan yang diatur dalam PSAK 24, dan owner merasa tidak terlalu perlu untuk melakukan pengalokasian dana karena karyawan masih merupakan relasi keluarga dari owner sendiri. Walaupun demikian owner tetap berinisiatif untuk membayar imbalan pascakerja sesuai dengan ketentuan Undang-Undang walaupun tidak dianggarkan sesuai anjuran PSAK 24, tetapi membayar dengan menggunakan dana pribadi owner dengan jumlah yang ditentukan sesuai dengan kerelaan oleh owner sendiri.

Dari hasil wawancara dengan pada PT. Moy Veronika tidak menerapkan dan tidak mengalokasikan dana khusus dari kas perusahaan untuk program imbalan pasti bagi imbalan pascakerja karyawannya, sehingga tidak dilakukan pencatatan mengenai akuntansi imbalan pascakerja. Tidak adanya pengalokasian dana khusus dari kas perusahaan untuk program imbalan pasti dikarenakan owner tidak memiliki pengetahuan tentang anjuran pengalokasian dana dari kas untuk imbalan pascakerja terhadap karyawan yang diatur dalam PSAK 24 dan owner merasa tidak terlalu perlu untuk melakukan pengalokasian dana karena karyawan masih merupakan relasi keluarga dari owner sendiri. Walaupun demikian owner tetap berinisiatif untuk membayar imbalan pascakerja sesuai dengan ketentuan undang-undang.

\subsubsection{Penerapan Imbalan Pascakerja sesuai dengan Undang-Undang Ketenagakerjaan (UUK) No.13 Tahun 2003}

1. Mengundurkan Diri

Pada PT. Moy Veronika sudah pernah terjadi kasus mengundurkan diri atas kemauan sendiri, namun karyawan tersebut belum memenuhi syarat seperti yang ditetapkan pada UUK No. 13 tahun 2003 pasal 162 ayatnya yang ke (3), sehingga PT. Moy Veronika tidak berkewajiban untuk membayar kepada karyawannya yang mengundurkan diri sesuai dengan pasal 162 ayat (1), namun jika ada karyawan memenuhi ketentuan tersebut maka PT. Moy Veronika akan membayar sesuai dengan UUK No. 13 tahun 2003 pasal 162.

2. Meninggal Dunia

Sesuai dengan hasil wawancara pada PT. Moy Veronika, belum pernah terjadi kasus karyawan berhenti karena meninggal dunia, namun jika terjadi kasus tersebut maka PT. Moy Veronika akan membayar sesuai dengan UUK No. 13 tahun 2003 pasal 166.

3. Pensiun

Pada PT. Moy Veronika belum pernah terjadi kasus karyawan berhenti bekerja karena memasuki usia pensiun, alasan yang mendukung belum pernah terjadi kasus ini adalah umur perusahaan yang masih cukup muda, sehingga karyawan pada PT. Moy Veronika belum memenuhi syarat usia pensiun. Tetapi berdasarkaon hasil wawancara dengan manager dan owner pada PT. Moy Veronika jika nanti ada karyawan yang berhenti bekerja karena memasuki usia pensiun maka PT. Moy Veronika akan membayar imbalan pascakerja sesuai dengan UUK No. 13 tahun 2003 pasal 167 yang berlaku. Dalam hal ini PT. Moy Veronika tidak mendaftarkan pekerja sebagai peserta pada program pensiun, maka entitas diwajibkan mengikuti ketentuan UUK Pasal 167 ayat (5).

4. Pada PT. Moy Veronika sudah pernah terjadi kasus dimana karyawan berhenti bekerja karena sakit berkepanjangan/cacat. Pekerja berhenti sebelum 12 (dua belas) bulan dikarenakan mengalami sakit yang tidak memungkinkan bagi karyawan untuk dapat bekerja kembali, owner PT. Moy Veronika menanggung seluruh biaya pengobatan dan 
juga memberikan santunan yang sesuai dengan pasal 156 ayat (2), dalam pemberian pesangon sesuai dengan masa kerja yang kurang dari 1 (satu) tahun kepada karyawan tersebut, namun dikarenakan karyawan yang belum memasuki minimal masa kerja, dimana pada pasal 156 ayat (3) yang mencantumkan minimal masa kerja yaitu 3 (tiga) tahun, maka PT. Moy Veronika tidak memberikan uang penggantian masa kerja sesuai dengan ketentuan UUK No. 13 tahun 2003 pasal 156 ayat (3), dan owner juga memberikan biaya/ongkos kepada pekerjanya yang sudah tidak dapat kembali bekerja untuk pulang ke tempat dimana pekerja diterima. Sistem E-loan dan sistem SILK IDeb merupakan sistem yang diperlukan dalam pemberian kredit, sistem E-loan sebagai tempat untuk memproses pemberian kredit melalui data dan berbagai analisa dan keputusan, dan sistem SILK IDeb merupakan penyedia data informasi keuangan debitur. Untuk meningkatkan performa layanan dari sistem E-loan dan keakuratan data debitur secara lansung, sebaiknya sistem E-loan dapat terhubung dengan sistem SILK IDeb, dalam hal ini sistem E-loan bisa menganalisa informasi debitur dan melakukan penilaian kualitas/jumlah tunggakan dalam pemberian kredit yang dilakukan debitur pada lembaga keuangan lain, dan data diperoleh dapat dipercaya.

4.2.3. Jurnal yang dipakai dalam pengakuan imbalan pascakerja jika perusahaan mengalokasikan dana khusus untuk imbalan pascakeja.

Contoh perhitungan sebuah entitas yang mengalokasikan dana khusus untuk pekerjanya, adalah sebagai berikut :

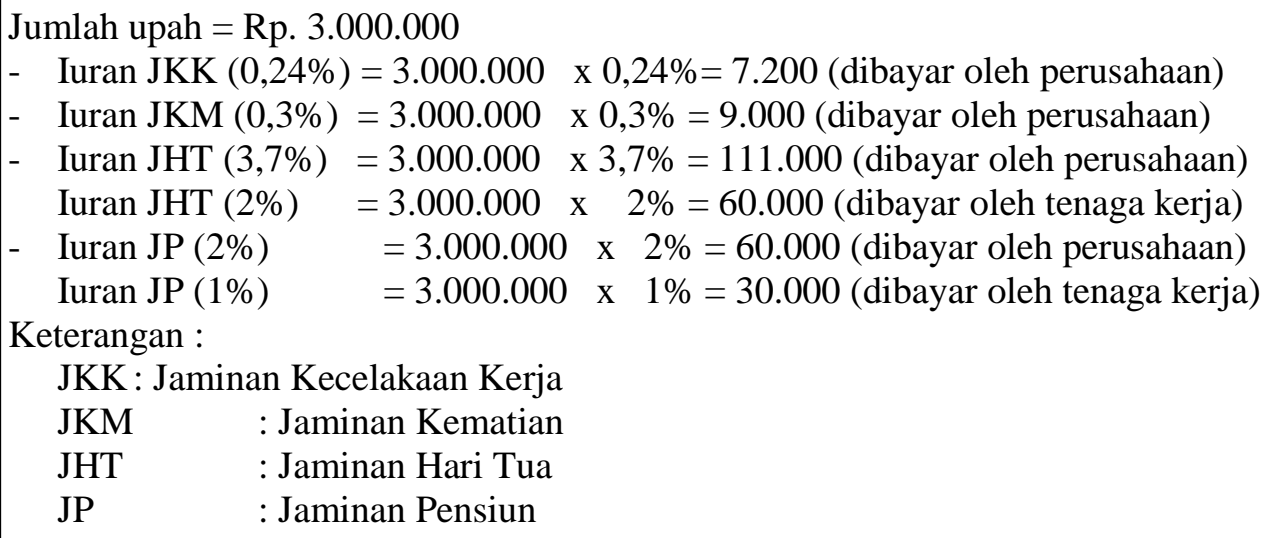

Dengan jurnal yang dipakai untuk iuran JKK, JKM, JHT, dan JP adalah sebagai berikut (untuk pengeluaran yang ditanggung dari kas perusahaan),

Beban iuran JKK (0.24\% dari jumlah upah)

Kas

Beban iuran JKM (0.3\% dari jumlah upah) Kas

Beban iuran JHT (3.7\% dari jumlah upah)

Beban iuran JHT (2\% dari jumlah upah) Kas

Beban iuran JP (2\% dari jumlah upah)

Beban iuran JP (1\% dari jumlah upah)

Kas

$\begin{array}{ll}7,200.00 & 7,200.00 \\ 9,000.00 & 9,000.00 \\ 111,000.00 & \\ 60,000.00 & \\ & 161,000.00 \\ 60,000.00 & \\ 30,000.00 & \\ & 90,000.00\end{array}$

$90,000.00$

\subsubsection{Penempatan Pos Imbalan Pascakerja pada Laporan Laba Rugi}

PSAK No 24 juga mengatur tentang pengungkapan atas imbalan kerja. Entitas harus mengungkapkan imbalan kerja jangka pendek untuk manajemen kunci berdasarkan PSAK 
No. 7 dan pengungkapan beban imbalan kerja dalam laporan keuangan berdasarkan PSAK No. 1. Perusahaan mengungkapkan beban imbalan kerja dalam Actual Profit and Loss sebagai bagian dari biaya operasional. PSAK No. 24 mengatur tentang pengungkapan atas imbalan pascakerja, dimana entitas mengungkapkan jumlah iuran untuk program iuran pasti (Lisa, 2015). Perusahaan ini tidak mengungkapkan jumlah iuran program pascakerja dalam laporan internal entitas (realisasi biaya operasional) sebagai bagian dari tunjangan dalam catatan atas laporan keuangan pada bagian informasi mengenai presentase iuran yang harus dibayarkan oleh perusahaan kepada program pascakerja.

Penelitian ini didukung dengan penelitian terdahulu yang dilakukan oleh Lisa (2015) dengan hasil penelitian objek yang diteliti telah menerapkan dengan baik pengakuan, pengukuran, dan pengungkapan imbalan kerja jangka pendek dan imbalan pascakerja. Persamaan dari penelitian tersebut dengan penelitian ini adalah sama-sama menganalisis kesesuaian penerapan PSAK 24 mengenai imbalan kerja, sementara perbedaannya pada penelitian ini dikhususkan dalam membahas imbalan pascakerja saja, dan hasil penelitian ini juga diukung dengan penelitian dari Liapis \& Thalassinos (2013) yang mengemukakan tentang perlindungan hak imbalan pascakerja yang dapat dilindungi oleh Undang-Undang. Persamaan dari penelitian ini adalah sama-sama membahas tentang imbalan pascakerja, namun perbedaanya tidak adanya pembahasan tentang PSAK 24 karena perbedaan negara dengan standar akuntansinya.

\section{KESIMPULAN DAN SARAN}

\subsection{Kesimpulan}

Berdasarkan hasil penelitian dan pembahasan sebelumnya, maka peneliti dapat disimpulkan beberapa hal sebagai berikut :

1. PT. Moy Veronika tidak menerapkan standar akuntansi dalam pemberian imbalan pascakerja, sehingga entitas tidak melakukan pengakuan, pengukuran, pengungkapan.

2. Penerapan pemberian imbalan pascakerja di PT. Moy Veronika sudah sesuai dengan UUK No.13 Tahun 2003, dalam hal terjadinya pemutusan hubungan kerja yang disebabkan karena : 1. mengundurkan diri; 2. meninggal dunia; 3. pensiun; 4. sakit berkepanjangan/cacat. Hal ini berarti pengusaha sudah memenuhi kewajiban dalam pemberian imbalan pascakerja.

3. Ditemukan bahwa faktor-faktor yang menyebabkan tidak adanya pencatatan transaksi imbalan pascakerja yaitu:

a. Karena tidak adanya pengetahuan tentang pencatatan akuntansi khususnya tentang imbalan pascakerja.

b. Tidak adanya sosialisasi mengenai tata cara pencatatan akuntansi imbalan pascakerja sesuai dengan PSAK 24

c. Karyawan PT. Moy Veronika masih ada hubungan keluarga sehingga owner merasa tidak perlu untuk mencadangkan biaya imbalan pascakerja

4. Perlakuan dan pembayaran imbalan pascakerja pada PT. Moy Veronika sudah sesuai dengan ketentuan UUK No. 13 Tahun 2003

\subsection{Saran}

1. PT. Moy Veronika diharapkan dapat mengalokasikan dana khusus untuk imbalan pascakerja demi tercapainya visi dan misi perusahaan, dan menghindari pengeluaran kas yang akan mengganggu arus kas saat terjadinya hal-hal yang tidak direncanakan.

2. Bagian keuangan khususnya bagian akuntansi agar mempekerjakan karyawan yang kompeten dibidang akuntansi.

3. Pemilik PT. Moy Veronika agar dapat memisahkan antara kehidupan perusahaan dan kepentingan pribadi dari owner sendiri. 


\section{DAFTAR PUSTAKA}

Anantharaman \& Chuk. 2015. The Economic Consequences Of Accounting Standards: Evidence From Risk-Taking In Pension Plans. Journal.

Arine. B. G. 2016. Analisis Penerapan Imbalan Kerja: Kesesuaiannya dengan PSAK 24 Revisi 2013 Tentang Imbalan Kerja (Studi Kasus Dilakukan Pada PT. X) Universitas Gadjah Mada. Yogyakarta.

Darodjat, T. A. 2015. Pentingnya Budaya Kerja Tinggi dan Kuat. Aboslute. Penerbit Refika Aditama.

ED PSAK 242014

Hery. 2013. Akuntansi Dasar 1 \& 2. PT Gramedia Widiasarana Indonesia. Jakarta

Lam, Nelson., Lau, Peter. 2012. Intermediate Financial Reporting Second Edition. Mc Graw Hill. Singapore

Lisa. Londong. I. 2015. Analisis Pengakuan, Pengukuran Dan Pengungkapan Imbalan Kerja Berdasarkan Psak No. 24 Tentang Imbalan Kerja Pada PT. Hasjrat Abadi Manado. Universitas Sam Ratulangi. Mando. Jurnal Emba Volo.3 No.4.

Paath, C. L. A. 2015. Evaluasi Penerapan PSAK 24 Revisi 2010 Mengenai Imbalan Kerja Khususnya Imbalan Setelah Bekerja Pada Bank Sulut. Universitas Sam Ratulangi. Manado. Jurnal EMBA Vol. 3 No. 1.

Watung M. N. 2016. Analisis Penerapan PSAK 24 Mengenai Imbalan Kerja Pada PT. Bank Maybank. Universitas Sam Ratulangi. Manado. Jurnal EMBA Vol.4 No.4

Reeve et al, 2012. Principles of Financial Accounting 12th Edition International University of Georgia Jonathan Duchac, Wake Forest University 960pp Published by Cengage Learning, (C)2012

Sadarmayanti \& Hidayat. 2011. Metodologi Penelitian. Bandung: Mandar Maju.

Sugiyono. 2014. Metode Penelitian Bisnis (Pendekatan Kuantitatif, Kualitatif dan R\&D). Alfabeta, Bandung.

Suryabrata. 2013. Metodologi Penelitian. Jakarta Utara: PT Raja Grafindo Persada. 